\title{
Cystic Fibrosis of the Pancreas: Involvement of MUC6 Mucin in Obstruction of Pancreatic Ducts
}

\author{
Colm J. Reid,* Karen Hyde,* Samuel B. Ho, ${ }^{\dagger}$ Ann Harris* \\ *Paediatric Molecular Genetics, Institute of Molecular Medicine, \\ University of Oxford, John Radcliffe Hospital, Oxford, U.K. \\ tDepartment of Gastroenterology, Veterans Affairs Medical Center, \\ University of Minnesota, Minneapolis, Minnesota, U.S.A.
}

\begin{abstract}
Background: Cystic fibrosis (CF) is characterized by pancreatic destruction following the gradual obstruction of small pancreatic ducts, from the mid-trimester of gestation onwards. To date, the material causing the obstruction has not been identified. The MUC6 mucin cDNA was isolated from human stomach and has been shown to be expressed in a number of other tissues in the gastrointestinal tract, including the gall bladder and parts of the ileum and colon.

Materials and Methods: We have examined the expression of MUC6 mucin in the human pancreas, both during development and postnatally, by mRNA in situ hybridization and immunocytochemistry.
\end{abstract}

Results: In this report we establish that MUC6 transcripts are abundant in pancreatic epithelial cells and show a very similar pattern of expression in the epithelium lining small ducts and centroacinar cells to that shown by the cystic fibrosis transmembrane conductance regulator gene (CFTR). In addition, material obstructing the pancreatic ducts of CF pancreas was shown to contain MUC6 mucin.

Conclusion: We have identified MUC6 mucin as a significant constituent of the material obstructing the small pancreatic ducts in CF.

\section{INTRODUCTION}

Cystic fibrosis (CF) is characterized by pancreatic insufficiency due to destruction of the pancreas. The precise cause of the destruction has generally been thought to be obstruction of the pancreatic ducts by inspissated secretions. These secretions may include mucous glycoproteins and other proteins; however, the composition of the secretions has not been defined. One of the earliest pathological manifestations of CF in utero is the deposition of periodic-acid Schiff-positive material in the fetal pancreatic ducts at about 12 weeks of gestation (1). We have shown that the cystic fibrosis transmembrane conductance regulator (CFTR) gene (2), that is mutated in CF, is

Address correspondence and reprint requests to: Ann Harris, Paediatric Molecular Genetics, Institute of Molecular Medicine, University of Oxford, John Radcliffe Hospital, Oxford OX3 9DU, U.K. Tel: 44-1865-222341; Fax: 441865-222626; email: aharris@worf.molbiol.ox.ac.uk. expressed by 12 weeks of gestation in the fetal pancreatic duct epithelium (3-5). We have now identified MUC6 as a major pancreatic mucin that is expressed by 13 weeks of gestation and shows a pattern of distribution that is very similar to that of CFTR from this age through to adult life. The localization of expression of MUC6 mRNA has been confirmed with a polyclonal chicken antibody raised against a synthetic peptide corresponding to a tandem repeat region of MUC6 (6). Further, we have shown in fetal CF pancreas that the MUC6 mucin is a significant constituent of the material that causes the characteristic obstruction of small ducts.

\section{MATERIALS AND METHODS}

Tissues from mid-trimester terminations were obtained with local ethical committee approval and age was determined on the basis of foot 
length. Pancreas samples were from four fetuses of 13 weeks gestation and one each of 16.5, 23, and 24.5 weeks. Postnatal pancreas tissues were obtained from organ donors and were from 2-, 17- and 19-year-old males. Two CF pancreases were analyzed. One was from a male $\Delta \mathrm{F} 508$ homozygote who was born prematurely at 28 weeks gestation and died 21 days later from respiratory failure, at an age equivalent to 31 weeks gestation $(28+3$ weeks). The second was a 29-week intrauterine death due to intestinal rupture. The fetus was diagnosed on the basis of pathology consistent with CF and was heterozygous for $\Delta \mathrm{F} 508$ and an undefined mutation. Tissues for in situ hybridization were fixed directly in $4 \%$ paraformaldehyde ( $\mathrm{pH} 9.5$ ) overnight at $4^{\circ} \mathrm{C}$, and embedded and frozen in liquid nitrogen prior to cutting $10-\mu \mathrm{m}$ sections. Frozen sections were mounted onto Vectabond-treated slides (Vector Laboratories) and stored dessicated at $-20^{\circ} \mathrm{C}$ until used.

\section{In Situ Hybridization}

In situ hybridization was carried out as described previously (5). The following probes were used: for MUC6, a 74-bp double-stranded oligonucleotide GGTCCACACACACAGCCCCACCAGTGA CGCCGACCACCAGTGGGACGAGCCAAGCCGC GAGCTCATTCAGCACA) (bases 308-381 EMBL Accession number L07517) with additional bases to enable direct cloning into the BamHI and HindIII sites of pBluescript. Antisense and sense MUC6 ${ }^{35} \mathrm{~S}$-labeled riboprobes were generated from the $\mathrm{T} 7$ and $\mathrm{T} 3$ promoters, respectively. The antisense (HCF-3) and sense (HCF-4) ${ }^{35}$ S-labeled cRNA probes for CFTR were generated from an EcoRl/Xbal fragment (exons 1-5, bases 62-645) as described previously (5). Purified probes were diluted to $5 \times 10^{6}-2 \times 10^{7} \mathrm{cpm} / \mathrm{ml}$ in a hybridization solution containing formamide (final concentration $60-65 \%$ ), $1 \times$ Denhardt's solution, $10 \%$ dextran sulphate, $0.5 \mathrm{mg} / \mathrm{ml}$ RNase-free transferRNA (tRNA), and $10 \mathrm{mM}$ dithiothrietol (DTT).

Tissue sections were digested with $10 \mu \mathrm{g} / \mathrm{ml}$ proteinase $\mathrm{K}$ for $2 \mathrm{~min}$ at $37^{\circ} \mathrm{C}$, then treated with $25 \mathrm{mM}$ acetic anhydride in $0.1 \mathrm{M}$ triethanolamine ( $\mathrm{pH} \mathrm{8.0)}$ for $10 \mathrm{~min}$ at room temperature; they were briefly rinsed in $2 \times$ SSC before dehydrating quickly through a graded ethanol series and air dried. As a control for nonspecific binding of the antisense probe, some sections were treated with $20 \mu \mathrm{g} / \mathrm{ml}$ RNase A for $15 \mathrm{~min}$ at room temperature before incubation with proteinase $\mathrm{K}$.
Hybridization was done overnight at $55^{\circ}-$ $60^{\circ} \mathrm{C}$. Post-hybridization, slides were washed four times in $4 \times$ SSC at room temperature and digested with RNase A for $30 \mathrm{~min}$ at $37^{\circ} \mathrm{C}$. Sections were washed at a final stringency of $0.1 \times$ SSC at $60^{\circ} \mathrm{C}$ or $70^{\circ} \mathrm{C}$ for 30 min and dehydrated. Slides were exposed to Kodak Nuclear Tracking (NTB-2) liquid emulsion for $10-14$ days at $4^{\circ} \mathrm{C}$. The slides were developed, fixed, and counterstained with hematoxylin and eosin.

\section{Immunocytochemistry}

6- $\mu \mathrm{m}$ sections were cut from the same paraformaldehyde-fixed, frozen tissues that were used for in situ hybridization experiments. Sections were rehydrated in phosphate-buffered saline (PBS) and then treated with $0.225 \% \mathrm{H}_{2} \mathrm{O}_{2}$ in $80 \%$ methanol for $20 \mathrm{~min}$. Sections were subsequently exposed to (a) 1:3000 diluted M6P (antiMUC6) chicken antipeptide polyclonal serum (2), preimmune serum or PBS for $1 \mathrm{hr} ;(b)$ 1:1000 diluted peroxidase-conjugated rabbitanti-chicken immunoglobulins for $\mathrm{l} \mathrm{hr}$; and (c) biotinylated swine anti-rabbit immunoglobulins for $1 \mathrm{hr}$. The M6P antibody recognizes a 23 amino acid synthetic peptide (KPPFTTHSPPTGSSPFSS TGPMT) located within the 169-amino acid tandem repeat unit of the MUC6 mucin. Preabsorption of the M6P antibody with MUC6 synthetic peptide largely abolished its reactivity. Peroxidase label was then visualized with the Strept$\mathrm{ABC}$ complex/HRP kit (Dako) according to the manufacturer's instructions. Tissue sections were stained with hematoxylin.

\section{RESULTS}

\section{MUC6 MRNA}

Abundant MUC6 mRNA expression was detected throughout the pancreatic duct epithelia and the developing acini at or by 13 weeks of gestation, the earliest fetal age examined (Fig. IA-C). A similar pattern of expression was seen at 23 weeks (Fig. 2A-C). MUC6 expression patterns in a $28+3$ week $\Delta \mathrm{F} 508 \mathrm{CF}$ pancreas appeared normal (Fig. 2G-I). In postnatal pancreas (Fig. 3A-D) MUC6 expression was seen in interlobular and intralobular duct epithelial cells, centroacinar cells, and possibly acinar cells (the in situ technique might not enable discrimination between centroacinar cells and acini). There was substantially less MUC6 mRNA in larger pancre- 

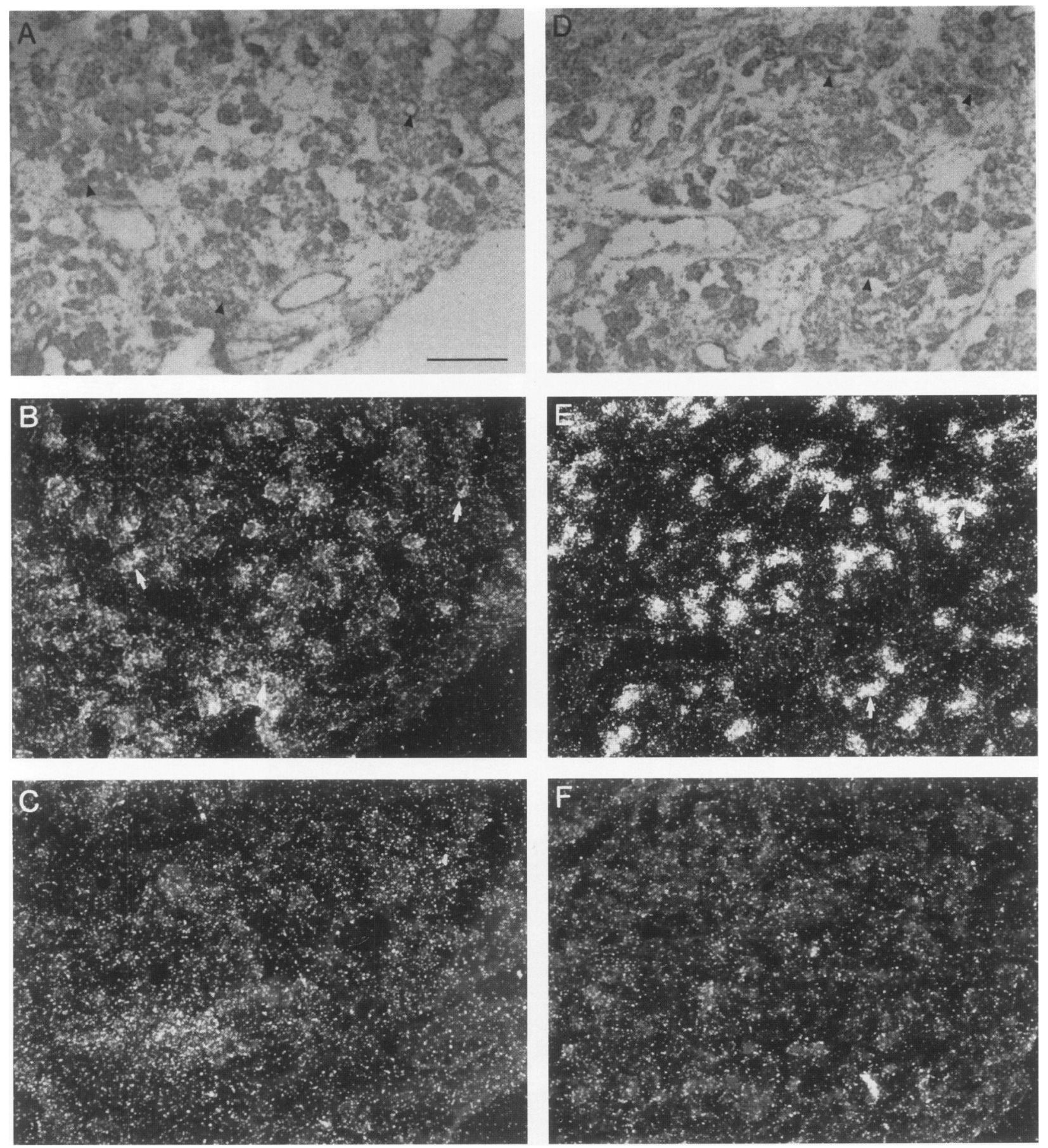

FIG. 1. Expression of MUC6 and CFTR MRNA in 13-week pancreas

Expression of MUC6 mRNA (A-C) and CFTR (D-F) in 13-week fetal pancreas. Panels A and D show bright-field views of pancreas sections hybridized with the MUC6 and CFTR antisense probes, respectively, and panels B and E show dark-field images of the same sections. Panels $C$ and F show dark-field views of consecutive sections hybridized with the MUC6 and CFTR sense negative control probes, respectively. Arrowheads in panels A and D and arrows in panels B and E denote interlobular and intralobular ducts. Scale bar $=200 \mu \mathrm{m}$ for all panels. 

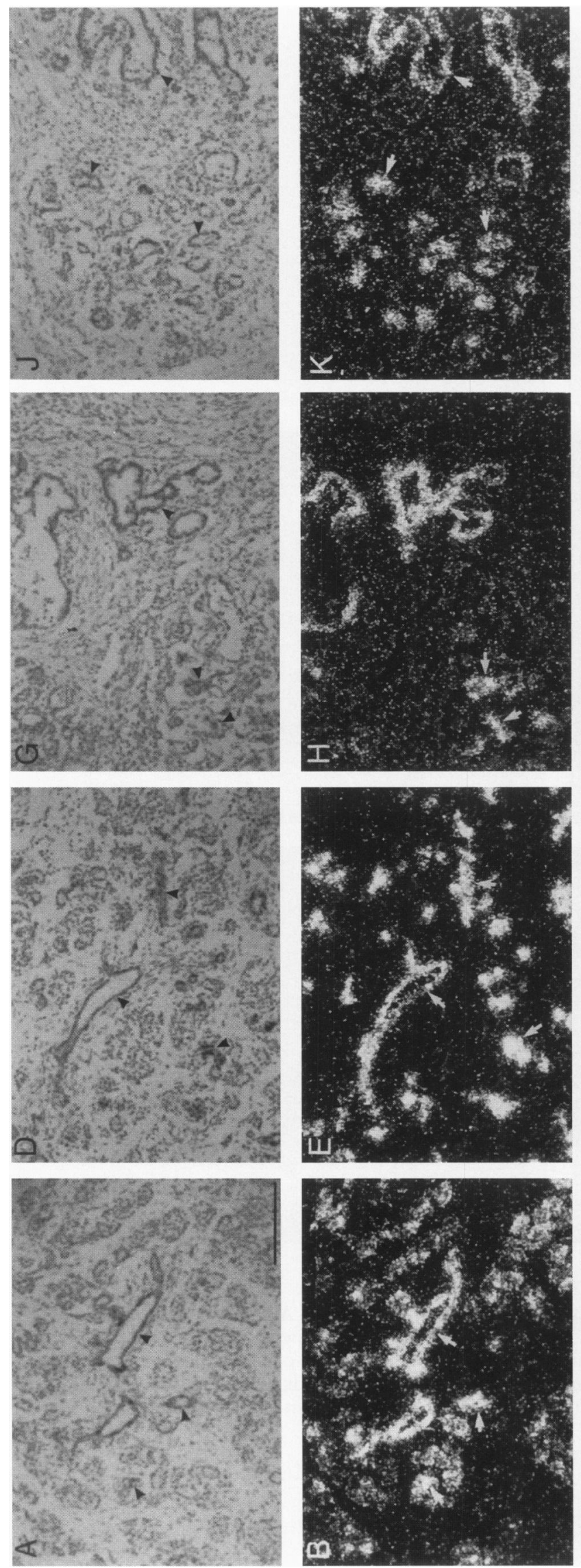
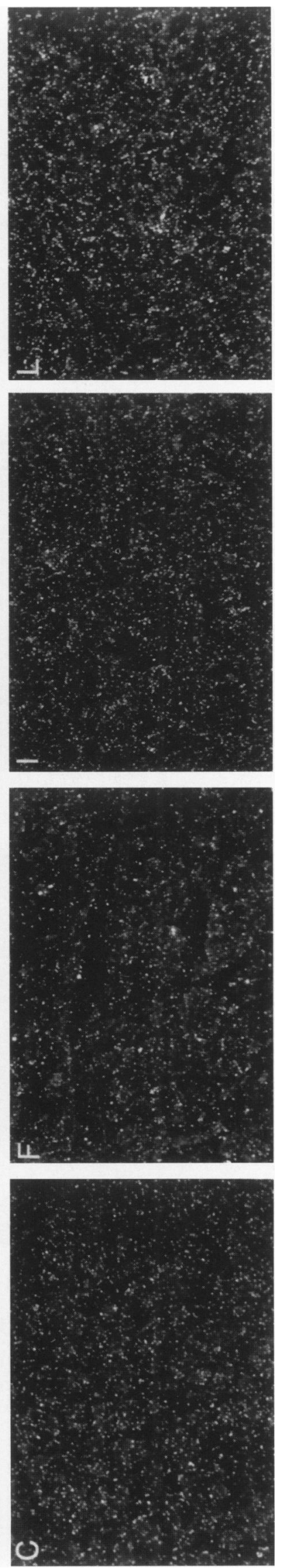

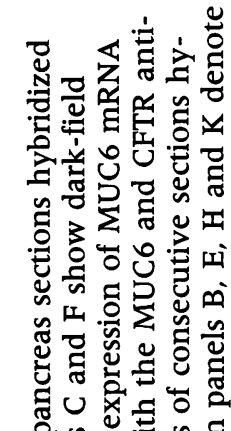

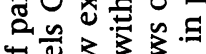

प्ष is के

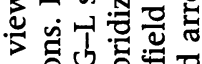
을

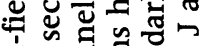

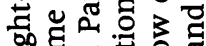

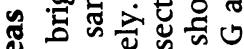

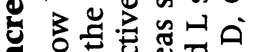
สี ज्ञ

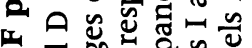
过 สี

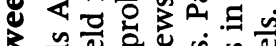

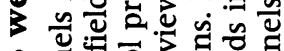

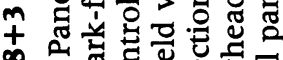

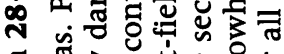

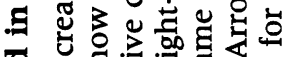

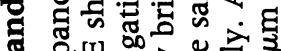

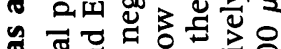

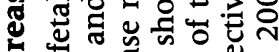

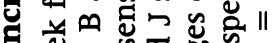

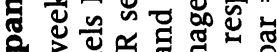
4 解可产

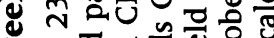

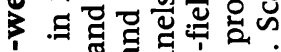

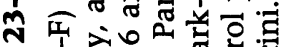

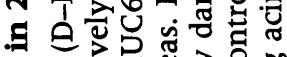

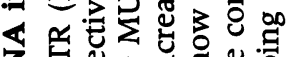

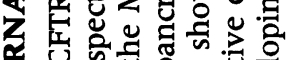
है

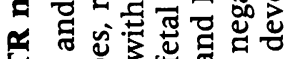
덩 응현 江

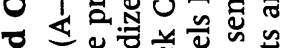
ส $\varangle$ 舫

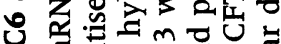

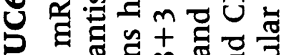
$\sum$ نั 。号焉.

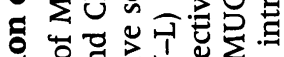
응 눌

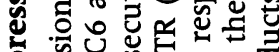

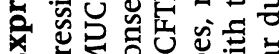

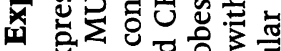

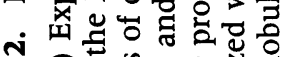

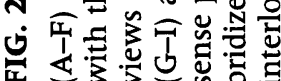



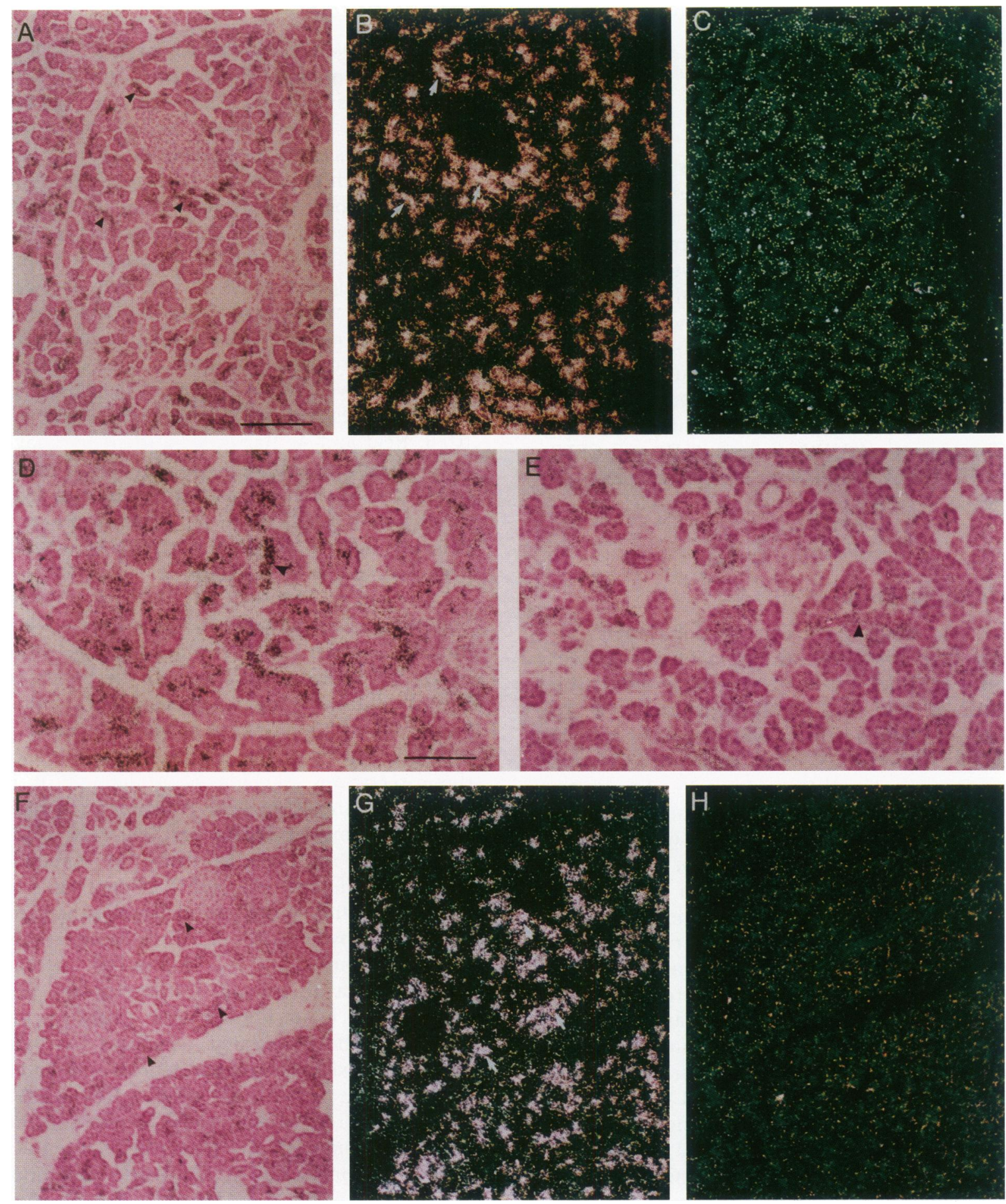

FIG. 3. Expression of MUC6 and CFTR mRNA in 2-year-old pancreas

Expression of MUC6 mRNA (A-D) and CFTR (E-H) in 2-year-old pancreas. Panels A and D show bright-field views of pancreas sections hybridized with the MUC6 antisense probe; panels E and F show bright-field views of pancreas sections hybridized with the CFTR antisense probe. Panels B and G show dark-field images of the same sections shown in panels $\mathrm{A}$ and $\mathrm{F}$. Panels $\mathrm{C}$ and $\mathrm{H}$ show dark-field views of consecutive sections hybridized with the MUC6 and CFTR sense negative control probes, respectively. Arrowheads in panels A, D, E and F and arrows in panels B and $G$ denote interlobular and intralobular ducts and centroacinar cells. Scale bar $=200 \mu \mathrm{m}$ for panels $\mathrm{A}-\mathrm{C}$ and $\mathrm{F}-\mathrm{H}$; scale bar $=100 \mu \mathrm{m}$ for panels $\mathrm{D}$ and $\mathrm{E}$. 
atic duct structures and no detectable expression in islets.

\section{CFTR MRNA}

Data presented in Figs. 1 (panels D-F) and 2 (panels D-F) show CFTR expression in fetal pancreas at 13 and 23 weeks, respectively, within pancreatic ducts (interlobular, intralobular, and centroacinar cells) and within developing acini. No CFTR mRNA is detectable in the pancreatic islets. A $28+3$ week $\Delta \mathrm{F} 508 \mathrm{CF}$ pancreas showed the same pattern of expression of CFTR (Fig. 2J-L). CFTR and MUC6 transcripts have nearly identical expression patterns in the 13and 23-week fetal pancreas. A similar pattern of colocalization of MUC6 (panels A-D) and CFTR mRNA (panels $\mathrm{E}-\mathrm{H}$ ) is seen in postnatal pancreas (Fig. 3).

\section{MUC6 Glycoprotein}

The M6P antibody, a chicken polyclonal antibody that was raised against a MUC6 tandem repeat peptide, was used to localize the MUC6 glycoprotein in normal and CF pancreas (Fig. 4). Panels A-D show hematoxylin and eosin-stained sections of normal 32-week gestation fetal pancreas (panels A and B) and the $28+3$ week CF pancreas (panels $C$ and $D$ ). An abnormal histology is apparent in the CF pancreas with material obstructing dilated ducts (see arrow in panel D). MUC6 protein expression is seen in 23-week pancreas in developing pancreatic ducts and acini (panels E-G; E, preimmune serum, F and G, M6P). The arrow in panel $G$ identifies MUC6 expression in developing acini/centroacinar cells. MUC6 protein expression in a 2-year-old normal pancreas is illustrated in panels $\mathrm{K}-\mathrm{M}(\mathrm{K}$, preimmune serum, $\mathrm{L}$ and $\mathrm{M}, \mathrm{M} 6 \mathrm{P})$. The arrow in panel $M$ shows acinar expression of MUC6 which is also seen in the epithelial cells lining small ducts and in centroacinar cells. Panels H-J show MUC6 protein expression in $28+3$ week $\mathrm{CF}$ fetal pancreas detected by the M6P antibody. The arrows in panels I and J show MUC6 to be a significant component of the material obstructing the small intralobular ducts in this $\mathrm{CF}$ pancreas. Similar results were obtained on a 29-week CF fetal pancreas, in which the histology was less abnormal but there was also evidence of MUC6 in inspissated sectetions within the intralobular ducts (not shown).

\section{DISCUSSION}

The MUC6 CDNA was isolated by expression cloning from a human stomach cDNA library $(6,7)$. The cDNA has not been fully characterized but appears to be at least $15-16 \mathrm{~kb}$ long. Similar to other mucins, MUC6 contains a serine- and threonine-rich tandem repeat sequence with an individual repeat unit of $507 \mathrm{bp}$ and 169 amino acids. The gene maps to chromosome $11 \mathrm{pl}$ 15.41 lp15.5. MUC6 was initially reported to be expressed at highest levels in stomach and gall bladder, and weaker expression was detected in the terminal ileum and right colon. Subsequent studies confirmed this localization of expression and also showed MUC6 mRNA in the endocervix (8). In studies reported here and elsewhere (9) (C. J. Reid and A. Harris, submitted), we have investigated the temporal and spatial expression of MUC6 in several organs through human fetal development by mRNA in situ hybridization and detected high levels of MUC6 mRNA in fetal, postnatal, and adult pancreas.

The finding that MUC6 is detected throughout the normal human pancreatic duct epithelium is significant to our understanding of the biology of mucous secretions in the pancreas. Histochemical staining of pancreatic duct epithelia has shown the presence of mucin-like glycoproteins; however, the precise composition of these secretions has not been defined. It is known that the $M U C l$ gene is expressed at high levels by some pancreatic epithelial cell types (10). MUCl mRNA is detectable in the midtrimester pancreas (11) and is evident later in gestation in the epithelium of larger pancreatic ducts (12); however, this mucin-like core protein is not gel-forming and it is in part cell surfaceassociated via an integral transmembrane domain. MUCl is not known to be a major component of the inspissated secretions that are found in CF pancreas and its temporal and spatial patterns of expression are distinct from CFTR. Hence, MUC1 is unlikely to be involved in the initial pathobiochemical events that lead to ductal obstruction in CF. At 13 weeks gestation, MUC3 (13) mRNA is evident in the main pancreatic duct, though not elsewhere in the pancreas (C. J. Reid and A. Harris, submitted), and hence does not account for CF pathology. MUC2 (14), MUC3 (13) and MUC5B (15) transcripts have been detected in adult pancreas (5) though not in fetal tissues.

Thus, it is of particular interest in the context of $\mathrm{CF}$ that the localization of expression of the 

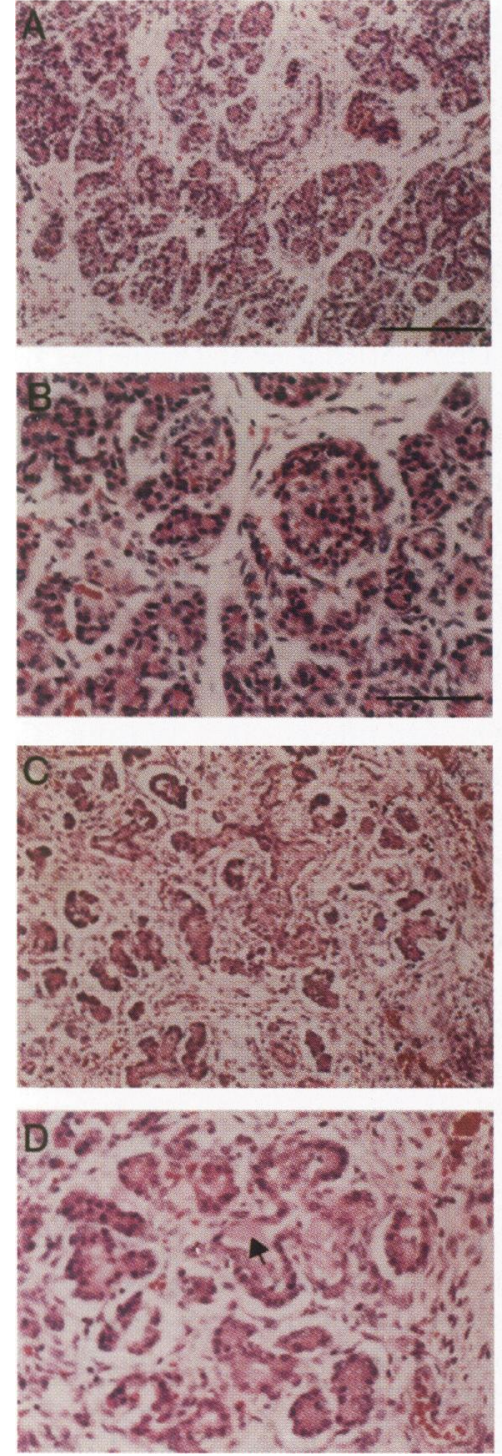
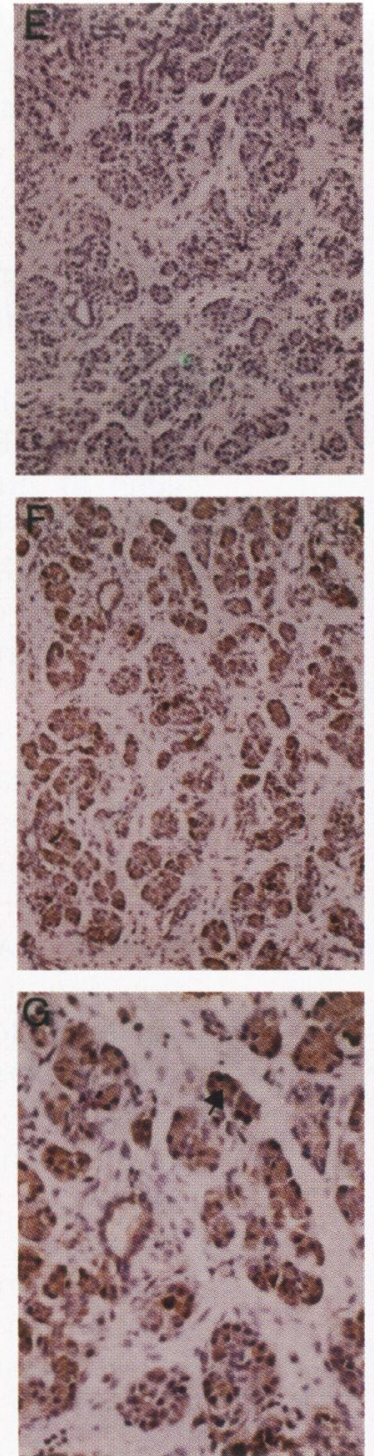
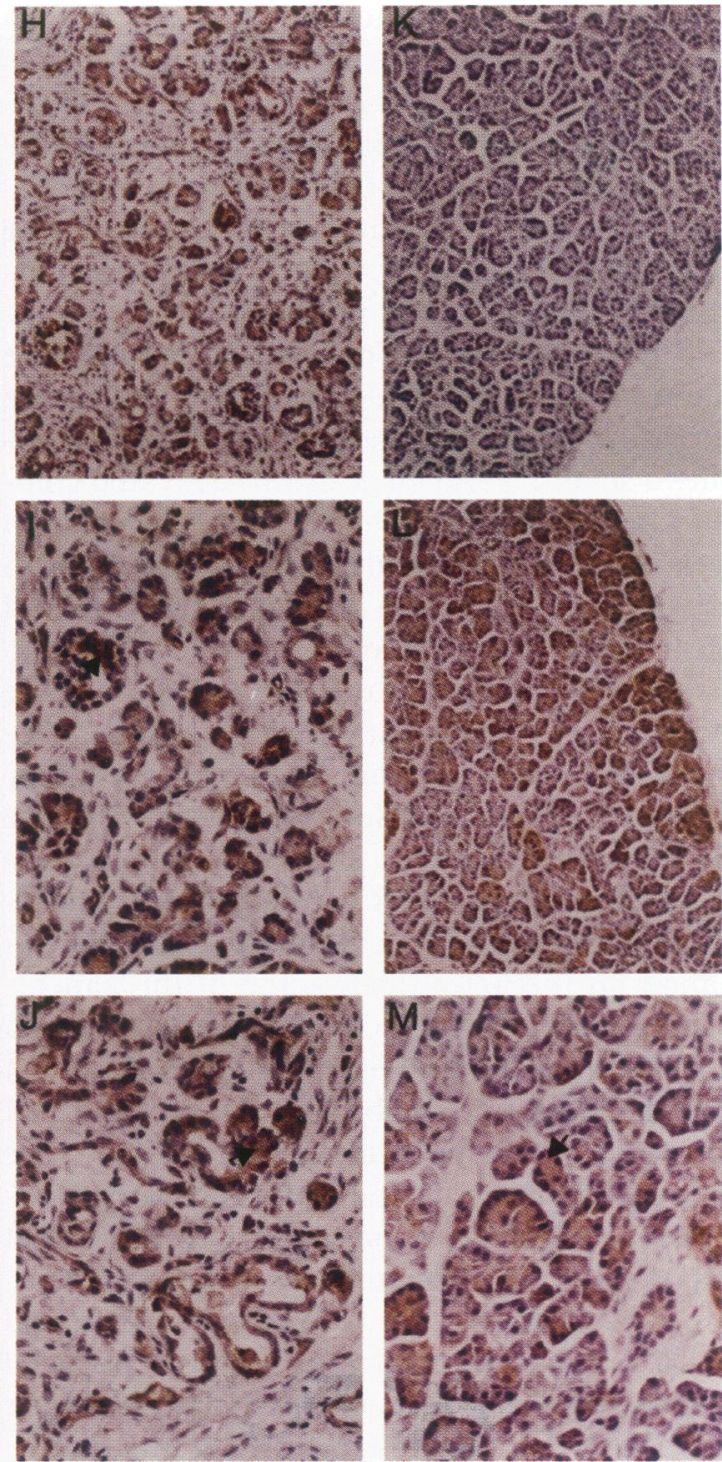

FIG. 4. Expression of MUC6 protein in 32-week- and 2-year-old normal pancreas and $28+3$ week CF pancreas

Immunoperoxidase detection of MUC6 protein in the pancreas. Panels A-D, hematoxylin and eosin-stained pancreatic tissue; A and B, normal 32-week pancreas; C and D, 28+3 week CF fetal pancreas. Panels E-G show MUC6 protein expression, detected with the M6P antibody, in 23-week pancreas; E, preimmune serum, F and G, M6P. Panels H-J show MUC6 protein expression in 28+3 week CF fetal pancreas. Panels K-M show MUC6 protein expression in 2-year normal pancreas; $\mathrm{K}$, preimmune serum, $\mathrm{L}$ and $\mathrm{M}$, M6P. Scale bar $=200 \mu \mathrm{m}$ for panels A,C,E,F,H,K and L; size bar $=100 \mu \mathrm{m}$ for panels B,D,G,I,J and $M$. See text for more discussion.

CFTR gene coincides with that of MUC6 in the pancreas. The temporal and spatial distribution of MUC6 and CFTR transcripts show complete concordance in the pancreas (Figs. 1-3). These results suggest that MUC6 and CFTR are expressed in the same cell types within the pancreas. We have previously verified that CFTR mRNA expressed in fetal pancreatic ducts is translated into CFTR protein (5). Data in this report show that MUC6 mucin glycoprotein, as detected by the M6P polyclonal antiserum, is present in the cell types that express the MUC6 gene-specifically, in developing acini/centroacinar cells and within small ducts at 23 weeks and 13 weeks (not shown), and in acini, centroacinar cells, and epithelial cells lining small ducts in a 
2-year-old normal pancreas. Further, though neither the pattern of expression nor the gross abundance of MUC6 transcripts was altered in the pancreas of a $28+3$ week $\Delta \mathrm{F} 508$ homozygote $C F$ baby, post mortem, MUC6 mucin was a significant component of the material obstructing the small intralobular ducts. (These data were confirmed in a 29-week CF pancreas).

These observations may be of considerable importance to our understanding the disease process in the CF pancreas. The CFTR gene encodes a small-conductance cAMP-activated chloride ion channel (17) that is expressed at high levels in the pancreatic duct epithelium in utero and postnatally (18). A principal physiological defect in the CF pancreas is one of failure to secrete bicarbonate ions that are essential for the normal flow of pancreatic duct secretions. One model that would explain the pathophysiology of $\mathrm{CF}$ in the pancreas, for which there is some physiological evidence, proposes that chloride ion efflux through CFTR is coupled to bicarbonate ion secretion via a chloride/bicarbonate exchanger in the apical membrane of the pancreatic duct cell (19). The CF pancreatic duct fluid has reduced water and bicarbonate content (20) and is believed to contribute to the deposition of material in the small intralobular ducts. The composition of these deposits has not been characterized, although it has been suggested that they may contain secreted proteins and/or mucus glycoproteins. We have now identified MUC6 as a significant constituent of these ductal deposits. Future experiments will determine the relationship between altered CFTR functioning and the solubility of MUC6. In summary, the identification of MUC6 as a major pancreatic mucin may have significant implications for the further investigation of a number of important pancreatic diseases, including cystic fibrosis and chronic pancreatitis.

\section{ACKNOWLEDGMENTS}

We are grateful to Simon Biddolph, Zahra Madgwick, and Drs. Stephen Gould and Lamont Weide for their assistance; also to Drs. M. A. Hollingsworth and N. Toribara for helpful discussions and Professor R. Moxon for his support. This work was supported by the Cystic Fibrosis Research Trust and grant DK46589 from the National Institutes of Health.

\section{REFERENCES}

1. Boué A, Muller F, Nezelof C, et al. (1986) Prenatal diagnosis in 200 pregnancies with a 1-in-4 risk of cystic fibrosis. Hum. Genet. 74: 288-297.

2. Riordan JR, Rommens JM, Kerem B-S, et al. (1989) Identification of the cystic fibrosis gene: Cloning and characterisation of complementary DNA. Science 245: 1066-1073.

3. Harris A, Chalkley G, Goodman S, Coleman L. (1991) Expression of the cystic fibrosis gene in human development. Development 113: 305-310.

4. Foulkes AG, Harris A. (1993) Localization of expression of the cystic fibrosis gene in human pancreatic development. Pancreas 8: 3-6.

5. Trezise AEO, Chambers JA, Wardle CJ, Gould S, Harris A. (1993) Expression of the cystic fibrosis gene in human fetal tissues. Hum. Mol. Genet. 2: 213-218.

6. Ho S, Robertson AM, Shekels LL, Lyftogt CT, Niehans GA, Toribara NW. (1995) Expression cloning of gastric mucin complementary cDNA and localization of mucin gene expression. Gastroenterology 109: 735-747.

7. Toribara NW, Robertson AM, Ho S, et al. (1993) Human gastric mucin. J. Biol. Chem. 268: $5879-5885$.

8. De Bolos C, Garrido M, Real FX. (1995) MUC 6 apomucin shows a distinct normal tissue distribution that correlates with lewis antigen expression in the stomach. Gastroenterology 109: 723-734.

9. Meier PB, Ewing SE, Evans MK, Toribara NW, Ho SB. (1996) MUC6 mucin is highly expressed in normal and neoplastic pancreas tissue and periductular biliary glands. Gastroenterology 110: A417.

10. Lan MS, Batra SK, Qi W-N, Metzgar RS, Hollingsworth MA. (1990) Cloning and sequencing of a human pancreatic tumor cDNA. J. Biol. Chem. 265: 15294-15299.

11. Batra S, Metzgar RS, Hollingsworth MA. (1992) Human MUCl mucin gene expression in fetal pancreas. Pancreas 7: 391-393.

12. Chambers JA, Hollingsworth MA, Trezise A, Harris A. (1994) Developmental expression of mucin genes MUC1 and MUC2. J. Cell Sci. 107: 413-424.

13. Gum J, Hicks J, Swallow DM, et al. (1990) Molecular cloning of cDNAs derived from a novel human intestinal mucin. Biochem. Biophys. Res. Commun. 171: 407-415. 
14. Gum JR, Hicks JW, Toribara NW, Rothe A-M, Lagace RL, Kim YS. (1992) The human MUC2 intestinal mucin has cysteine-rich subdomains located both upstream and downstream of its central repetitive region. J. Biol. Chem. 267: 21375-21383.

15. Aubert JP, Porchet N, Crepin M, et al. (1991) Evidence for different human tracheobronchial mucin peptides deduced from nucleotide cDNA sequences. Am. J. Respir. Cell Mol. Biol. 5: 178-185.

16. Balague C, Audie J-P, Porchet N, Real FX. (1995) In situ hybridization shows distinct patterns of mucin gene expression in normal, benign and malignant pancreas tissue. Gastroenterology 109: 953-964.
17. Crawford IC, Maloney PC, Zeitlin PL, et al. (1991) Immunocytochemical localization of the cystic fibrosis gene product CFTR. Proc. Natl. Acad. Sci. USA 88: 9262-9266.

18. Anderson MP, Rich DP, Gregory RJ, Smith AE, Welsh MJ. (1991) Generation of cAMPactivated chloride currents by expression of CFTR. Science 251: 679-682.

19. Gray MA, Greenwell JR, Argent BE. (1988) Secretin-regulated chloride channel on the apical plasma membrane of pancreatic duct cells. J. Membr. Biol. 105: 131-142.

20. Kopelman H, Durie PD, Gaskin K, Weisman Z, Forstner G. (1985) Pancreatic fluid secretion and protein hyperconcentration in cystic fibrosis. N. Engl. J. Med. 312: 329-334.

Communicated by D. Weatherall. Accepted April 9, 1997. 